\title{
AFINIDADES ENTRE DWORKIN Y POUND. UN BREVE ESTUDIO SOBRE INFLUENCIAS Y COINCIDENCIAS
}

César Arjona

ESADE

\section{Introducción}

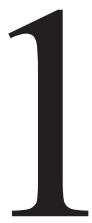

1. Objeto. El objeto del presente estudio es establecer y analizar afinidades entre la obra de dos de los más grandes juristas norteamericanos del siglo XX: Roscoe Pound y Ronald Dworkin. El término 'afinidad' es portador de una

ambigüedad en la que me apoyo deliberadamente. Sugiere tanto la existencia de relaciones de causalidad como de meras coincidencias (Burnet 1985: 244).

Roscoe Pound (1870-1964) ha sido considerado como el jurista teórico [legal scholar] más importante de todos los tiempos en Estados Unidos (Summers 1984: 428). Durante años fue la figura más destacada en la filosofía jurídica de aquel país. ${ }^{1}$ Su teoría, comúnmente conocida con el nombre de jurisprudencia sociológica, marcó el desarrollo del Derecho estadounidense tanto en su dimensión teórica como práctica durante los comienzos y mediados del siglo XX. Además, su conocimiento erudito de otras culturas jurídicas y el carácter universalista de su obra lo convirtieron en referente más allá de las fronteras de su país. Su influencia, sin embargo, declinó ya en los últimos años de su longeva carrera y hoy, incluso en muchos sectores del Derecho norteamericano, Pound ha caído en el olvido o es objeto de una atención puramente retórica. ${ }^{2}$

Por el contrario, Ronald Dworkin (1931-) es posiblemente el filósofo del Derecho más influyente en la actualidad. El carácter internacional de esa in-

${ }^{1}$ El propio Dworkin se refirió a él como "the playing captain of American legal philosophy for decades" (Dworkin 1967: 215).

${ }^{2}$ Para quien esté interesado en una aproximación biográfica a Roscoe Pound, la obra más recomendable es Wigdor 1974. Una versión en lengua española, más reducida pero muy reveladora y que contiene las circunstancias esenciales de la vida de Pound, puede encontrarse en el primer capítulo de García Ruiz 2002. 
fluencia iguala y supera al de Pound. La obra de Dworkin constituye la base de muchos programas docentes y de investigación en centros académicos de todo el mundo y resulta difícil pensar que alguien que se dedique a la filosofía del Derecho no esté en alguna medida al corriente de su obra.

Existen muchos puntos de contacto entre Pound y Dworkin. Por razones que indicaré más abajo, no resulta sencillo determinar cuándo Pound ejerció una influencia sobre Dworkin o cuándo la correspondencia es casual. De entre todos los aspectos en los que existe esa correspondencia, aquí escogeré dos que me parecen especialmente significativos, y procederé a un análisis sucinto de las semejanzas y sus implicaciones. En relación con uno de ellos, la distinción entre reglas y principios, existen razones para pensar que Dworkin fue conscientemente influido por Pound. En el caso del segundo, esto es, la distinción entre derechos y objetivos, que tiene su paralelo en la contraposición poundiana entre intereses individuales y sociales, parece existir más bien una significativa coincidencia.

Este trabajo presupone cierta familiaridad con la obra de Ronald Dworkin. Las cuestiones de su teoría de las que aquí se trata son de las más conocidas y las introduciré sin mayor presentación. Por el contrario, sí presentaré, con carácter previo a la comparación, los conceptos pertinentes de Pound, por ser éste un autor en general poco conocido por el jurista español.

1.2. Objetivos. El objetivo de este trabajo es de carácter esencialmente académico. Se trata de dejar establecido que en Pound se prefiguran algunas de las tesis básicas de Dworkin y planteada la posible influencia, hasta ahora poco destacada en la literatura, del primero sobre el segundo. Junto con el anterior, se pretende una revalorización del pensamiento de Roscoe Pound, un autor cuyo prestigio actual dentro y fuera de Estados Unidos no hace justicia a su verdadera importancia.

Paralelamente, este trabajo supone un acercamiento real al contenido de una pequeña parte de la obra de Pound, una obra sugerente y en buena medida imperecedera, por consistir ante todo en direcciones generales de pensamiento. ${ }^{3}$ Las obras de Pound cumplen una función dinamizadora: su visión y talento para plantear grandes temas jurídicos contrastan con las ambigüedades y contradicciones internas que lastran el desarrollo de los mismos. Que lo poco que aquí presento de Pound pueda servir de inspiración, ya sea para interpretar a Dworkin o ya sea con cualquier otro fin, es algo que depende tanto del lector como del autor de estas páginas, quien, si eso sucediera, habría visto superados con creces los objetivos que se planteaba al escribirlas.

\footnotetext{
3 Tomo prestada la expresión de Robert S. Summers, quien la utiliza, por ejemplo, en Summers 1982: 19.
} 
1.3. Nota metodológica. El objeto de este estudio presenta ciertas particularidades metodológicas que me interesa destacar. Ya he hecho referencia a la dificultad de establecer la influencia de Pound en Dworkin. La causa de esa dificultad hay que buscarla en ambos autores.

Pound ejerció una gran influencia tanto en el mundo práctico como en el de la academia (Sayre 1948: 360; Patterson 1968: 395). Pero aunque buena parte de esa influencia fue directa (y quedó reflejada en citas y referencias), la mayor parte fue una influencia indirecta. Esto es, Pound contribuyó de manera importante en la creación de una atmósfera intelectual que fue el origen de importantes desarrollos. Pero tanto el grado de esa contribución como sus consecuencias son muy difíciles de determinar. Que la influencia ejercida por Pound fuera sobretodo indirecta es consistente con su estilo: la brillantez de Pound se manifestó, como se acaba de decir, al nivel de direcciones generales de pensamiento más que de cuestiones particulares. Este tipo indirecto de influencia puede ser tanto o más importante que la influencia directa, pero resulta difícil de probar.

En cuanto a Dworkin, no hace falta más que consultar cualquiera de sus obras principales para percatarse de que su esmero a la hora de citar y referirse a otros autores es sólo relativo. Aunque algunos de sus textos están sazonados con extensas notas, es cosa conocida en la comunidad académica que Dworkin no es el autor más riguroso en cuanto a la identificación de sus fuentes. Es por eso que a menudo resulta especialmente dificultoso trazar el origen de algunas de sus ideas y arriesgado establecer quién y cómo le ha influido.

La conjunción de estos dos factores dificulta la tarea de determinar qué tipo de correspondencia existe entre Dworkin y Pound y justifica que prefiera referirme a sus puntos de contacto como afinidades.

1.4. Fuentes. La literatura específica sobre la comparación entre Dworkin y Pound es muy escasa. Dado que la obra de Dworkin ha generado un cuerpo muy nutrido de literatura secundaria, las causas de aquella escasez parece que pueden deberse o bien a falta de literatura sobre Pound o bien a falta de interés en la comparación en sí. Ambas alternativas se combinan. En relación con la falta de interés por la comparación, hay que tener en cuenta las dificultades metodológicas recién planteadas, que sin duda no han servido para estimular esta vía de investigación. En cuanto a la falta de interés en Pound, ésta merece una reflexión aparte.

Hay un "hueco" en la literatura jurídica en torno a Pound (Hull 1997: 2). ${ }^{4}$ Aunque existen (y esto tiene algo de paradoja) muchos artículos y libros

\footnotetext{
${ }^{4}$ Ese hueco también se extiende a otros campos relacionados por su contenido con el pensamiento de Pound, como la sociología (Treviño 1997: xxii) o la filosofía (Martin 1965: 37).
} 
sobre Pound, normalmente ofrecen una visión parcial y fragmentaria de la obra de este autor. El hueco, pues, se refiere a la ausencia de estudios generales y comprensivos sobre el pensamiento y la relevancia de Pound. Existen unos pocos, pero insuficientes, tanto cuantitativa como cualitativamente, sobretodo cuando se los compara con la literatura generada por otras figuras de alcance e importancia no superiores a los de Pound. ¿Por qué esto? Dentro de las causas que pueden haber desanimado de distintas maneras a los estudiosos se encuentran la vastísima extensión de su obra, el eclecticismo de su filosofía o su importancia como figura pública. ${ }^{5}$ Su gran longevidad no tuvo, en este sentido, un efecto positivo: durante las últimas décadas de su vida Pound añadió bastante poco a su trabajo anterior y se dejó llevar por la rutina de la repetición, cada vez menos sentida y a veces algo adulterada, de lo ya escrito y de lo ya dicho, lo cual derivó en falta de interés por parte de los juristas entonces jóvenes (Patterson 1953: 511). Desde una perspectiva más amable con el Decano Pound, puede aducirse que tal fue la influencia que ejerció durante los primeros años de su carrera, que sus ideas quedaron completamente integradas en la cultura jurídica, neutralizándose así su originalidad y la atracción por el hombre que las formuló. Cabe decir en ese sentido que Pound fue víctima de su propio éxito (Treviño 1997: xliv).

Hasta donde llega mi conocimiento, la única fuente dedicada exclusivamente al estudio comparado de estos dos autores es un breve artículo publicado por David Burnet hace casi veinte años (Burnet 1985). Dentro de otros trabajos, destaca el capítulo sexto de la obra The Politics of Jurisprudence, de Roger Cotterrell, en el que se trata de forma conjunta y exclusiva a Dworkin y Pound (Cotterrell 1992). ${ }^{6}$ En nuestro país, García Figueroa en su libro Principios y positivismo jurídico ha dedicado un breve epígrafe al tratamiento de Pound como antecedente de Dworkin (García Figueroa 1998). ${ }^{7}$ Más allá de esto, desconozco la existencia de algún estudio conjunto sobre Pound y Dworkin en nuestro país. ${ }^{8}$ Finalmente, hay que destacar una fuente en la que el propio Dworkin trata sobre Pound. Se trata de una sucinta

\footnotetext{
${ }^{5}$ Se puede decir con seguridad que la faceta de hombre público repercutió negativamente en la calidad académica del trabajo de Pound. Como dato más destacado dentro de aquella faceta, hay que señalar que Pound fue decano de la Harvard Law School durante veinte años (19161936). La importancia que tuvo ese cargo en su imagen la demuestra el hecho de que después de renunciado al mismo se le siguiera conociendo como Decano Pound [Dean Pound].

${ }^{6}$ Pp. 150-181: "6. The Problem of the Creative Judge: Pound and Dworkin".

${ }^{7}$ Se trata del epígrafe "1.4.5. Roscoe Pound: un antecedente de Dworkin”, pp. 127-130.

${ }^{8}$ Ni García Figueroa 1998 (en las páginas relevantes) ni García Ruiz 2002 (en su monografía sobre Pound, la primera en España según el propio autor) hacen referencia a pieza alguna en este sentido.
} 
crítica que aquél escribió para acompañar la publicación póstuma de la pieza de Pound titulada The Case for Law (Dworkin 1967).

\section{Reglas y principios}

2.1. Reglas y principios en la filosofía jurídica: el cisma del positivismo jurídico. La discusión acerca de los principios jurídicos y de su distinción con las reglas es una de las más importantes de la filosofía jurídica contemporánea. Las tesis sobre los principios más divulgadas y debatidas son las de Ronald Dworkin. ${ }^{9}$ Su contenido es bien conocido. Dworkin construye su teoría como un ataque frente al positivismo jurídico en su versión más sofisticada, la de H.L.A. Hart. El positivismo, según Dworkin, ve el ordenamiento jurídico como un sistema normativo compuesto exclusivamente por reglas, ${ }^{10}$ las cuales son identificadas como tales por la manera en que son adoptadas o desarrolladas (lo que Dworkin denomina su pedigree). Sin embargo, cuando los juristas razonan utilizan estándares distintos a las reglas, como son los principios, algo que, arguye Dworkin, el positivismo ha olvidado (Dworkin, 1970).

La crítica de Dworkin es de gran relevancia, ya que ataca las tres tesis básicas del positivismo, a saber, la tesis de las fuentes sociales del Derecho, la tesis de la separación conceptual entre Derecho y moral y la tesis de la discreción judicial (Moreso 2002: 94). La tesis de las fuentes sociales del Derecho, según la cual la pertenencia de normas a un sistema jurídico depende de una serie de hechos sociales (en Hart, la regla de reconocimiento), quiebra, dado que los principios no son susceptibles de ser identificados por medio de un test semejante a la regla de reconocimiento (en términos de Dworkin, por su pedigree). Su pertenencia al Derecho no la determina la manera en que son creados sino su contenido. La tesis de la separación conceptual entre Derecho y moral, según la cual ni la validez jurídica de una norma implica su bondad moral ni de la bondad moral de una norma puede derivarse su validez jurídica, también quiebra, ya que para Dworkin la pertenencia de un principio al sistema jurídico no se produce, como se acaba de decir, por hechos socialmente comprobables sino precisamente por el valor moral de su contenido. La validez jurídica de los principios sí deriva de su bondad moral. Finalmente, la tesis de la discreción judicial, según la cual cuando ninguna regla es aplicable a un caso en cuestión el juez es libre de ejercer su discreción para llegar a una solución, cae también, ya que en

\footnotetext{
${ }^{9}$ Sin embargo, sobre los principios habían escrito ya en Europa ilustres juristas muchos años antes de que lo hiciera Dworkin en Estados Unidos (véase Atienza y Ruiz Manero 1996: 3; García Figueroa 1998: 92 y ss.).

${ }^{10}$ Caracterización, por cierto, discutida (Raz 1972: 845).
} 
esos casos, si bien es cierto que las reglas se agotan, el juez debe recurrir a los principios, los cuales permiten, dicho gráficamente, cerrar el sistema normativo. De esto último, me ocupo con mayor extensión más adelante.

Estas críticas someramente presentadas de Dworkin han recibido múltiples respuestas. Entre ellas, destacadamente, las del propio Hart en el postcript a su obra magna, El concepto de Derecho (Hart 1994). Esas respuestas, a menudo tan o más convincentes que los ataques de Dworkin, han reforzado en cualquier caso la importancia de sus críticas, pues han llevado a la adopción de distintas posturas dentro del seno del positivismo hasta el punto de haberse producido algo parecido a una escisión en dos corrientes que se han dado en llamar positivismo jurídico excluyente y positivismo jurídico incluyente (Moreso 2002: 94-95). En términos muy generales, el positivismo jurídico incluyente se caracteriza por "aceptar que los principios morales substantivos pueden ser parte del Derecho de una comunidad en virtud de su estatus como principios morales siempre que la regla de reconocimiento relevante incluya una provisión a ese efecto" (Coleman 1996: 287-88). La mayoría de los filósofos del Derecho contemporáneos se adhieren a alguna forma de positivismo jurídico incluyente. ${ }^{11}$ Entre ellos, el propio Hart, quien concedió que "en algunos sistemas jurídicos (...) el criterio último de validez jurídica puede incorporar explícitamente, además del pedigree, principios de justicia y valores morales substantivos" (Hart 1994: 247). Esta versión del positivismo es sensible a la crítica de Dworkin, ya que incorpora los principios como estándares jurídicos que crean obligación, pero mantiene su carácter positivista, ya que está comprometida con la regla de reconocimiento como criterio de pertenencia de una norma al sistema (Coleman 1996: 288). Los criterios de pertenencia, pues, siguen siendo convencionales, pero esa convención puede remitir al valor moral de la norma, con lo cual se da entrada a los principios tal como los concibe Dworkin (Bayón 2002: 70).

El positivismo jurídico excluyente, por el contrario, niega a los principios el carácter de Derecho obligatorio y no considera la posibilidad de recurrir al valor moral de un estándar para determinar su pertenencia al sistema. El defensor más ilustre de esta posición es Joseph Raz. Por la misma razón por la que los positivistas incluyentes entienden que Dworkin, al dirigir sus críticas contra el positivismo hartiano, yerra el blanco de las mismas (García Carrió 1990: 234), los ataques de Dworkin parecen más apropiados contra una posición de corte excluyente. De hecho, Dworkin y Raz comparten una misma caracterización de lo que es el positivismo: ambos sostienen que las normas jurídicas sólo pueden ser identificadas en último término en base a

${ }^{11}$ Para un tratamiento general de esta versión del positivimo véase Waluchow 1994, Coleman 2001, Himma 2002. 
convenciones sociales sin que éstas puedan remitirse al valor moral de los estándares, esto es, sin que la regla de reconocimiento pueda incorporar criterios de naturaleza moral (Perry 1997: 814). Por eso dice Waluchow que Raz y Dworkin son aliados; aliados, se entiende, en su deseo por minar el positivismo jurídico incluyente (Waluchow 1994: 83).

2.2. Influencia de Pound en Dworkin. Esbozada la importancia que las tesis de los principios tienen en la filosofía jurídica contemporánea, cabe decir que la principal de esas tesis, esto es, que en el sistema jurídico existen principios, los cuales son normas tan obligatorias jurídicamente como las reglas pero distintas a las mismas, fue ya formulada por Pound. ${ }^{12}$ En términos similares a los que más tarde utilizaría Dworkin, Pound apuntó como "la jurisprudencia analítica (...) inglesa y americana ha sido perniciosa al inculcar la idea de que el Derecho no es más que una agregación de leyes y que las leyes no son más que reglas que relacionan una consecuencia detallada y definida a un estado de hechos detallado y definido" (Pound 1967: 203). ${ }^{13}$

Es plausible pensar que en este punto Pound ejerció una influencia directa sobre Dworkin. El principal motivo para creerlo así es que Dworkin, de quien ya se ha dicho que no es prolífico en sus citas, reconoce el mérito y la originalidad de Pound en este particular. Dworkin En su artículo fundacional The Model of Rules, señala expresamente que Pound había ya diagnosticado la tendencia de los juristas a asociar el Derecho con una colección o sistema de reglas (Dworkin 1970: 52-53). ${ }^{14}$ En su crítica a la pieza de Pound The Case for Law, Dworkin reconoce el potencial de las líneas apuntadas por el Decano, en particular que el Derecho es más que un conjunto de reglas,

${ }^{12}$ Pound parece haber sido el primer norteamericano en presentar esta tesis. Ya se ha dicho que el tema de los principios se ha tratado también en Europa, y se ha hecho de forma contemporánea e incluso anterior a Pound. Dado el amplio conocimiento que éste poseía de la literatura jurídica europea parece normal suponer la influencia de algún autor europeo en esta materia. Sin embargo, no existen referencias explícitas de que eso fuera así: Pound no se apoya de manera especial en ningún autor ni teoría en el tema de los principios. Esa falta de referencias es muy significativa, ya que a la hora de citar y reconocer influencias Pound se congratulaba en mostrar su erudición (más aún cuando el objeto de la misma era la cultura no estadounidense) y sus referencias rayan el exceso. Se dice que el jurista norteamericano Harold Laski pensaba que Pound creía "en el derecho natural de todo alemán a ser citado" (Wigdor 1974: 285). Juristas tan destacados como Frankfurter y Holmes declaraban sentirse cansados ante el arsenal de títulos y nombres que Pound manejaba y expresaba en sus obras (Treviño 1997: vi; Wigdor 1974: 285). Por ello, el que Pound no remita a nadie más en su tratamiento de los principios, parece ser buen indicativo de su originalidad al respecto.

${ }^{13}$ Aunque el texto del que se extrae la cita se público póstumamente en 1967, constituye la base de una conferencia pronunciada por Pound en 1959.

${ }^{14}$ De hecho, si no estoy equivocado, en el texto de ese artículo, y dejando de lado alguna nota al pie, Dworkin sólo hace referencia a tres juristas: Austin, Hart y Pound, y a los dos primeros los trae a colación para tomarlos como blanco de sus críticas. Creo que eso deja bien a las claras la relevancia de la cita a Pound. 
que también hay principios, y que los principios "son Derecho en el sentido en que las reglas particulares lo son" (Dworkin 1967: 217). No cabe duda de que Dworkin explotó ese potencial en el desarrollo de su propia filosofía jurídica.

2.3. Pound sobre principios. El tratamiento de los principios por parte de Pound ocupa un breve espacio dentro de su ingente obra y no llega a un nivel de desarrollo suficiente como para poder hablar de una auténtica teoría de los principios. Lo esencial de lo que dice Pound en este contexto puede resumirse fácilmente.

Antes de todo, insisto en que su mayor valor radica en la tesis de partida, esto es, la inclusión de los principios como preceptos jurídicos distintos de las reglas pero con un carácter vinculante igual al de las reglas. Pound define una regla como un precepto jurídico que relaciona una consecuencia jurídica definida y detallada con un estado de hechos definido y detallado. El artículo de un código penal que impone un castigo por la comisión de un delito es un ejemplo de regla. También son ejemplos de reglas las normas que regulan la ejecución de los testamentos. Pound define un principio como un punto de partida del razonamiento jurídico dotado de autoridad a partir del cual deducimos reglas o razones en las que basar decisiones. Los principios no contemplan estados de hecho detallados y definidos ni consecuencias jurídicas detalladas y definidas. Como ejemplos de principio Pound se refiere al precepto según el cual quien culpablemente causa una pérdida a otro es responsable del daño o a aquél que prescribe que nadie debe enriquecerse injustamente a expensas de otro (Pound 1959: II, 125-26).

Los principios "son empleados continua y legítimamente en los casos que no están cubiertos o no están completa u obviamente cubiertos por reglas" (Pound 1933: 483). Los principios, dice Pound, organizan la experiencia (especialmente la experiencia judicial); sirven para diferenciar entre distintos casos y sitúan proposiciones generales tras las diferencias, explicando algunos casos por referencia a un punto de partida concreto y otros por referencia a un punto de partida diferente, o encontrando un punto de partida más inclusivo para el campo entero (Pound 1977: 45-46). A diferencia de las reglas, los principios no obtienen su mejor expresión en leyes escritas ni en decisiones judiciales sino en la doctrina (Pound 1933: 483). De hecho, son introducidos en el sistema principalmente a través del estudio y la enseñanza del Derecho (Pound 1944: 44). Aunque su presencia, señala Pound, es un elemento característico de los sistemas jurídicos desarrollados, en los estadios primitivos del Derecho puede encontrarse algo parecido a los principios en forma de proverbios o máximas jurídicas (Pound 1959: II, 126). 
Pound hace hincapié en la inviabilidad de un sistema jurídico compuesto exclusivamente por reglas. El ingenio humano siempre irá más lejos que las provisiones contenidas en esas reglas y por ello, dice Pound, los principios son necesarios ya que permiten justificar una decisión en aquellos casos donde no es aplicable ninguna regla. Esa necesidad se hace extrema en las sociedades industriales modernas. Dada la complejidad del orden económico-social contemporáneo, razona Pound, las reglas se muestran como claramente insuficientes en la tarea de mantener el control social. Para hacer frente a las múltiples y diversas controversias que emergen en un contexto permanentemente cambiante o bien recurrimos a la analogía o bien recurrimos a estándares más generales y flexibles que las reglas, estándares que pueden ser adaptados a diferentes situaciones de hecho, como son los principios. Los principios aparecen, en definitiva, como preceptos necesarios para mantener el orden económico (Pound 1944: 44-45).

De lo dicho se deduce que Pound no fue muy sofisticado tanto en la distinción interna como externa de los principios. Mejor dicho, no hay ningún tipo de distinción interna, ya que Pound no establece ninguna subcategorización dentro de los principios. En cuanto a la distinción externa hay que decir que el criterio de Pound para diferenciar reglas de principios no parece demasiado satisfactorio, ya que se refiere exclusivamente al grado de detalle y al carácter más o menos definido tanto de los casos o situaciones de hecho como de las consecuencias jurídicas enlazadas a los mismos. Los términos que definen el criterio son vagos y Pound no se ocupó de precisarlos. En ningún caso parece vislumbrarse la conocida distinción de Dworkin, según la cual las reglas se aplican en forma de todo o nada mientras que los principios tienen una dimensión de peso de la que carecen aquéllas (Dworkin 1970: 37-39). ${ }^{15}$ Por lo demás, la propia definición de principio de Pound es sólo relativamente clarificadora. Situada en el contexto de los muchos sentidos en que se ha utilizado el término 'principio', parece que a los que mejor se adapta su uso son los de principio como norma muy general, principio como norma cuyos términos son vagos y, posiblemente también, principio como máxima que proviene de la tradición jurídica (Atienza y Ruiz Manero 1996: 3; García Carrió 1990: 211). ${ }^{16}$

${ }^{15}$ El criterio de distinción de Dworkin ha sido a su vez criticado, entre otros, por García Carrió 1990: 226 y Hart 1994: 262.

${ }^{16}$ Cabe hacer notar que Atienza y Ruiz Manero señalan que las características de gran generalidad y vaguedad de los términos no son suficientes en sí mismas para distinguir a una norma como principio (Atienza y Ruiz Manero 1996: 5). 
2.4. Los principios y el problema de la discreción judicial. Pound comparte con Dworkin la preocupación por el papel de los jueces y la discreción judicial (Cotterrell 1992: 150-52). ${ }^{17}$ Acabamos de ver como Pound introduce los principios con la función de limitar la discreción judicial. El sistema capitalista y la economía de mercado requieren estabilidad jurídica y es por ello que resulta necesario un sistema de principios (estándares jurídicamente obligatorios) en que basar la toma de decisiones cuando un caso cae fuera del ámbito regulado por las reglas, de manera que el juez no quede obligado a decidir sin la ayuda de estándares jurídicos (Pound 1944: 45).

La posición de Dworkin en relación con la discreción judicial es bien conocida, pues ella constituye el núcleo de su controversia con el positivismo. ${ }^{18}$ Dworkin sostiene que no existe discreción judicial: para cualquier caso que se plantee, el sistema jurídico, compuesto por reglas y principios, ofrece una respuesta correcta. Dworkin incluye a Pound en una lista de defensores de la tesis de la discreción, es decir, de la tesis según la cual las dos únicas fuentes de decisión judicial son las reglas y la discreción, y cuando las reglas no determinan el resultado de un caso el juez encargado de decidirlo queda libre de sujeciones jurídicas para elegir la solución que considera más conveniente (Dworkin 1963: 624 n.1).

Esta consideración de Dworkin merece matizarse. De partida resulta curioso que tome a Pound como uno de los principales representantes de esa tesis, cuando él mismo reconocerá después el mérito del propio Pound en haber advertido que los estándares jurídicos obligatorios no se agotan en las reglas. Pero Dworkin tiene motivos para aquel inicial encasillamiento. Pound llegó a afirmar que la existencia de discreción judicial no es sólo inevitable, sino que en determinadas cuestiones puede ser ventajosa (Pound 1959: II 367-69). En su Teoría de la decisión judicial, Pound admitía que a la hora de determinar los materiales para resolver un caso, los jueces pueden buscarlos fuera del sistema jurídico, y que tal cosa es legítima y necesaria (Pound 1923: 948-49). Además, afirmaba que el poder del juez para decidir de acuerdo con su propia conciencia sin estar sometido al control de estándares es un elemento integrante de la moderna administración de justicia (Pound 1959: II 357-58).

Ahora bien, junto a las ideas que en este sentido se reproducen a lo largo de la obra de Pound, este autor elaboró una tesis algo más sofisticada en relación con la discreción judicial, la cual rompe con la dualidad entre regla

\footnotetext{
${ }^{17}$ Pound reconocía que su visión del derecho correspondía al punto de vista del juez (Pound 1933: 476).

${ }^{18}$ Hart mismo expresó que el desacuerdo más agudo entre Dworkin y él era el relativo al de la discreción judicial (Hart 1994: 272).
} 
y discreción que Dworkin le atribuye. ${ }^{19}$ En concreto, Pound planteó algo parecido a una concepción gradual de la discreción (Pound 1959: II 353; cf. Barak 1989: 36-41). Según ésta, el dualismo entre regla y discreción es una imagen simplista de la decisión judicial heredada del siglo XIX. Más bien, habría que hablar de cuatro tipos de casos frente a los que puede encontrarse el juez en el ejercicio de su función, los cuales son:

- $(\text { nivel } 0)^{20}$ casos que pueden ser resueltos mediante la aplicación de reglas.

- (nivel 1) casos que no están cubiertos por reglas pero pueden ser resueltos razonando a partir de principios.

- (nivel 2) casos que deben ser decididos mediante discreción ajustada a principios específicos sobre cómo ejercerla (discreción judicial).

- (nivel 3) casos que sólo pueden ser decididos mediante discreción sin referencia a ningún estándar dotado de autoridad (discreción personal).

Creo que es legítimo ver en la lista presentada una gradación de la discreción en el ejercicio de la función judicial. El primer nivel supone la ausencia absoluta de discreción, sería un nivel 0 de discreción. Ese nivel representaría el ideal de la jurisprudencia mecánica decimonónica, esa concepción de la función judicial como aplicación automática e incontrovertida de reglas que fue el objeto principal de las críticas del joven Pound pero que, según él mismo reconocía, no debía ser completamente descartada puesto que se adaptaba bien a muchas cuestiones jurídicas, como aquellas relacionadas con el derecho de propiedad o en general con las transacciones comerciales (Pound 1923: 825; cf Frank 1970: 221-31).

El segundo nivel rompe el dualismo regla-discreción y demuestra el importante papel que los principios juegan en la concepción de la discreción judicial de Pound, que prefigura el que jugarán en Dworkin. En efecto, tenemos ya un nivel 1 de discreción, que se presenta en aquellos casos en los que la aplicación "mecánica" de reglas no permite llegar sin más a una solución. Salvado el anacronismo, parece claro que este nivel de discreción equivale a lo que Dworkin ha denominado discreción débil. Concretamente, me refiero

\footnotetext{
${ }^{19}$ Esta atribución de dos tesis no del todo consistentes, la cual resultaría quizás excesivamente heterodoxa en relación con un autor más riguroso, tiene perfecta cabida en Pound. Dos aspectos deben resaltarse aquí. Primero, que Pound se movía a menudo en un gran nivel de abstracción sin dejar pistas claras respecto a cómo concretar sus teorías. Segundo, que las habilidades analíticas no fueron nunca las más destacadas de su pensamiento. Como resultado, algunos puntos de su obra pueden ser interpretados de muchas maneras e incluso él dejó apuntados caminos divergentes, cuando no contradictorios. Véase, en este sentido, el interesantísimo ejercicio que se realiza en un reciente artículo, cuyo autor plantea dos lecturas opuestas de un aspecto de la obra de Pound, reconociendo que ambas son posibles, legítimas y valiosas en sí mismas, sin que sea posible sintetizarlas (Lasser 2002).

${ }^{20}$ Esta y las siguientes denominaciones no son creación de Pound sino que las añado yo.
} 
al primer sentido de discreción débil, esto es, la que ejerce un juez cuando los estándares relevantes no son susceptibles de una aplicación mecánica y debe hacer uso de su discernimiento. Esta noción débil de discreción se contrapone al sentido fuerte del término, que hace referencia a la situación en la que el juez no está vinculado por ningún tipo de estándar jurídico. Este último es el sentido en el que Dworkin asegura que no existe discreción. Es a ese sentido fuerte al que se circunscribe la oposición de Dworkin con los positivistas (Dworkin 1970: 45-46).

Volviendo a Pound, podemos concluir que el nivel 1 de discreción corresponde a lo que Dworkin denomina discreción en sentido débil: los principios, al tiempo que vinculan al juez, le obligan a ejercer su buen juicio y discernimiento para llegar a la solución jurídicamente correcta.

¿Qué sucede con los dos últimos grados, los que pueden denominarse nivel 2 (discreción judicial) y nivel 3 (discreción personal)? Empecemos con la discreción judicial. En este ámbito, la ambigüedad de Pound es muy grande ya que no queda muy claro a qué se refiere cuando habla de "principios sobre cómo ejercer la discreción”. ¿Son estos algo distinto a los principios tal como han sido definidos con carácter general? ¿O no son distintos, en cuyo caso estaríamos hablando de casos que quizás requieren un plus de discernimiento por parte del juez pero que están aún controlados por los preceptos del sistema? Esta última opción parece cuando menos plausible. La definición más precisa de discreción personal en la obra de Pound se halla en un artículo que publicó en la última etapa de su carrera, cuando su principal preocupación había pasado a ser la defensa de los medios tradicionales del common law frente a la amenaza de la creciente intervención administrativa. Allí Pound define la discreción judicial como "un poder para determinar cuestiones a las que ninguna regla de Derecho es aplicable, las cuales se dejan al discernimiento del tribunal, que debe ser ejercido de acuerdo con principios establecidos" (Pound 1940: 42, cursiva añadida). $\mathrm{Si}$ eso debe interpretarse como el reconocimiento de discreción fuerte pero limitada o como discreción débil es pregunta a la que no puede responderse con seguridad, ya que estamos aplicando las categorías de forma anacrónica (algo por otra parte inevitable cuando se trata de comparar a dos autores no contemporáneos), pero la segunda posibilidad parece bastante admisible. En cualquier caso, la ambigüedad misma apoya la tesis de que la idea de discreción débil estaba de alguna forma presente en Pound (lo estaba sin duda en el nivel 1 de discreción y bien pudiera estarlo en el nivel 2), con lo cual hay argumentos para sostener que el pensamiento de Pound al respecto es más complejo de lo que Dworkin pareció asumir, y, por cierto, mucho más cercano al suyo propio. Confío en que esto se verá aún más claro cuando 
introduzca un nuevo elemento que sofistica todavía más la teoría de Pound: el de los ideales.

2.5. Los ideales prefiguran la tesis de la respuesta correcta. ¿Qué pasa con el nivel 3 de discreción, el de discreción personal? Aquí es donde la ambigüedad de Pound resulta más aguda, y, en cierto sentido, más fructífera. Por una parte, parece que Pound considera esta forma de tomar decisiones como discreción en sentido fuerte: la discreción personal le permite al juez decidir de acuerdo con su propia conciencia, sin control por parte de estándares dotados de autoridad (Pound 1959: II 358). Pero por otra parte, esto contrasta con lo que el mismo Pound dice en relación los niveles 2 y 3 de discreción, a saber, que en ellos "los ideales dotados de autoridad [authoritative ideals] restringen u orientan en mayor o menor medida la elección personal o el discernimiento del juez" (Pound 1959: II 354).

Describiré de forma muy breve qué son los ideales para Pound, lo cual me lleva a referirme sucintamente a su definición misma de Derecho. El Derecho puede definirse según Pound como "el sistema de materiales dotados de autoridad para motivar o guiar la acción judicial y administrativa reconocidos o establecidos en una sociedad políticamente organizada" (Pound 1959: II 106). ${ }^{21}$ A su vez, esos materiales se dividen en tres grupos: los preceptos, las técnicas y los ideales. Tanto las reglas como los principios son ejemplos de preceptos. Una técnica es una forma particular "de desarrollar y aplicar preceptos jurídicos mediante la cual esos preceptos son (...) extendidos, restringidos y adaptados a las exigencias de la administración de justicia (...). Son hábitos mentales que gobiernan el trabajo jurídico y judicial" (Pound 1959: II 107, 111). Nuestro mayor interés reside en los ideales. Un ideal es "una imagen del orden social en un momento y lugar determinados, una tradición jurídica al respecto de lo que ese orden social es y del fin o propósito del control social, imagen que constituye la base [background] de la interpretación y aplicación de preceptos jurídicos" (Pound 1959: II 116; en general, Pound 2002). Para ilustrar esta idea me referiré a uno de los ejemplos recurrentes que Pound utilizaba: el ideal al que los tribunales americanos se adherían a finales del siglo XIX, el cual consistía en la imagen de una sociedad con un máximo de asertividad individual en la que el gobierno debía limitarse a garantizar la seguridad general. Ese ideal, que estaba anquilosado en la América rural y pionera del pasado, era usado sistemáticamente por los tribunales para obstruir la entonces naciente

${ }^{21}$ Este es uno de los sentidos del término 'Derecho', que según Pound tiene tres. Los otros dos son Derecho como orden jurídico y Derecho como proceso jurídico (Roscoe Pound 1941: 249). No desarrollaré más este punto que no es estrictamente relevante para el propósito del presente artículo. 
legislación social y laboral. Con el paso del siglo, Pound constataba como un nuevo ideal, basado en la idea de cooperación, iba sustituyendo a aquél en los tribunales de su país (Pound 1936: 81).

De todo esto, la idea esencial para nuestro propósito es que los ideales no son preceptos jurídicos (como las reglas y los principios) pero sí son Derecho en el sentido más riguroso del término: son materiales jurídicos dotados de autoridad normativa que vinculan a los jueces. Y recordemos que incluso el nivel más fuerte de discreción, la discreción personal, está limitada por esos ideales. Pound afirma que si excluimos a los ideales de nuestra concepción del Derecho no sólo suprimimos un fenómeno de la mayor relevancia para la comprensión del funcionamiento real de la administración de justicia sino que, además, "perjudicamos mucho a los tribunales al dejar caer sobre ellos la acusación de decidir sin atender al Derecho [lawlessly] cuando hacen lo que deben hacer, y lo que los tribunales siempre han estado obligados a hacer cuando administran justicia de acuerdo a Derecho" (Pound 1959: II 122-23). Eso no parece corresponder con la concepción de la discreción como una zona de libertad donde el juez no está vinculado por estándares jurídicos. De hecho, Pound asegura que las principales líneas de los ideales están tan estrictamente fijadas como las del sistema de preceptos, esto es, como las reglas y los principios que habitualmente bastan para determinar la decisión de un caso. Y dice que la función de esos ideales es mantener la seguridad general y la estabilidad del sistema, al tiempo que permiten dirigir y organizar el crecimiento del Derecho (Pound 1923: 657).

Dicho todo eso, resulta bastante evidente que Pound se desmarca de una concepción simplista que vería en la decisión judicial una alternativa entre el seguimiento mecánico de reglas y la discreción ilimitada del juez cuando aquéllas no dictan la solución de un caso. El suyo no es, después de todo, el mejor ejemplo de la posición que Dworkin ataca. Más bien al contrario, su introducción de los ideales dotados de autoridad como orientadores de la decisión del juez incluso en los casos más difíciles prefigura la tesis de la respuesta correcta: el sistema siempre determina esa respuesta, aunque sea finalmente por medio de los ideales heredados sobre cuál es el fin o propósito del Derecho en la sociedad.

Cabría sugerir, por supuesto, que lo que propone Pound en su nivel 3 de discreción (y quizás también en su nivel 2) se parece más a un modelo de discreción fuerte limitada que a un modelo de discreción débil con respuesta correcta. Visto así, los ideales jugarían un papel de límite a la libertad del juez similar a otros que se han propuesto, como por ejemplo, el de la zona de razonabilidad (Barak 1989: 116-123). Como ya se ha dicho antes el anacronismo nos impide dar una respuesta definitiva. Aun así, creo que lo dicho anteriormente sobre los ideales (que sus líneas están bien fijadas, 
que garantizan la seguridad y la estabilidad del sistema) apunta a que éstos son algo dotado de un contenido más denso y más determinado que el de la zona de razonabilidad $\mathrm{u}$ otros criterios que se han sugerido para limitar la discreción en sentido fuerte. Dicho con otras palabras, si entendemos que Pound plantea un modelo de discreción en sentido fuerte, ésta está sometida a unas limitaciones que son, valga la redundancia, especialmente fuertes, además de tener un origen plenamente jurídico. Hasta tal punto eso es así, que resulta bastante plausible pensar en su concepto de discreción como una discreción en sentido débil en la cual ante cualquier caso difícil y después de mucho y difícil discernimiento un juez daría con la respuesta correcta tal como está determinada por el Derecho, esto es, tal como está determinada por los preceptos, la técnica para desarrollarlos y aplicarlos y, en último término, los ideales que engloban el contexto del razonamiento jurídico.

2.6. Los ideales prefiguran la concepción del 'Derecho como integridad'. Existen signos que permiten establecer una correspondencia entre los ideales de Pound y la concepción de Dworkin del Derecho como integridad. En su listado de estándares distintos a las reglas, los cuales limitan la libertad del juez y excluyen la discreción fuerte, Dworkin incluye los que llama "juicios de la comunidad", utilizados por los tribunales cuando éstos "invocan los ideales de la sociedad" (Dworkin 1963: 635, cursiva añadida). ${ }^{22}$ Ese elemento, como bien indica Dworkin, determina una oposición contra la tesis de la estricta separación entre los sistemas jurídico y moral de una comunidad, oposición que comparten Dworkin y Pound (en general, Pound 1926). Y es que la introducción de los ideales en el modelo de decisión judicial ofrece más resonancias de la teoría de Dworkin, al apuntar incluso hacia su concepción misma del Derecho como integridad (Dworkin 1986: 176-275).

Creo que merece la pena introducir una cita algo larga de Pound, por ser muy reveladora en este sentido.

"Los tribunales y los juristas de cualquier sistema jurídico desarrollado siempre han actuado en base a algo más que el cuerpo formal de preceptos jurídicos dotados de autoridad vigentes en su tiempo. Incluso el jurista analítico, que se jacta de trabajar completa y exclusivamente sobre las reglas que de hecho prevalecen en los tribunales de los estados modernos, en la práctica importa a su ciencia un modelo ideal de cómo esas reglas deben ser que en gran parte determina sus resultados. Él establece un esquema ideal [ideal plan] que le permitirá explicar tanto como sea posible del fenómeno actual de la administración de justicia y trata de conformar con el mismo lo que queda sin explicar" (Pound 1959: II 121, cursiva añadida).

\footnotetext{
${ }^{22}$ Por supuesto no estoy sugiriendo que Pound y Dworkin utilizasen el término 'ideal' con un mismo sentido, aunque la correspondencia terminológica es significativa.
} 
Si a eso se añade lo que ya sabemos, a saber, que esos ideales son los que guían al juez en la solución del caso difícil, creo que no resulta injustificado suponer que el juez que Pound tenía en mente se habría sentido bastante cómodo tratando de imitar a Hércules. El modelo de Dworkin, según el cual el jurista construye la mejor interpretación posible de las prácticas existentes en la comunidad y toma la decisión que mejor se ajusta a las mismas, se esboza en las palabras escritas por el Decano Pound. De hecho, dado que los ideales son para Pound una imagen de la comunidad política y del papel que el Derecho juega en ella, permiten la entrada en el razonamiento judicial de la filosofía política de una forma semejante a como lo hace Dworkin en su modelo de la integridad. En relación con ello, y aunque Pound nunca definiera un criterio de pertenencia al sistema jurídico, el que la decisión en los casos difíciles dependa del ideal político-jurídico que mejor se ajuste a las prácticas de la comunidad muestra la fusión de ser y deber ser, de teoría jurídica normativa y teoría jurídica descriptiva, que caracteriza el pensamiento de Dworkin, y que éste comparte también con Pound (García Figueroa 1998: 130).

Dworkin no sólo desarrolla infinitamente más que Pound, desde un punto de vista teórico, esta cuestión, sino que además se explaya en supuestos prácticos en los que muestra en acción la metodología de los jueces dentro de su concepción del Derecho como integridad. ${ }^{23}$ Ahora bien, aunque de forma embrionaria ésta fue esbozada por Pound. ¿Influencia o coincidencia?

\section{Intereses y derechos}

3.1. Derechos, objetivos e intereses. La distinción entre argumentos de principio y argumentos políticos [policy arguments], así como su análoga entre derechos y metas u objetivos [goals], que son centrales en la teoría de la decisión judicial de Dworkin, viene anticipada por la distinción establecida por Pound entre intereses individuales e intereses sociales (Burnet 1985: 240).

Para Pound el fin del Derecho es la satisfacción de intereses, definiéndose intereses como "las peticiones, demandas o deseos que los seres humanos, ya sea individualmente o en grupos, asociaciones o relaciones, tratan de satisfacer, los cuales, por tanto, se deben tomar en cuenta en la regulación de las relaciones y la ordenación de la conducta por medio de la fuerza de la sociedad políticamente organizada" (Pound 1943: 1). Los intereses son,

${ }^{23}$ Por poner un ejemplo, véase cómo Dworkin confronta a Hércules con un caso real y construye su razonamiento en 1986: 240 y ss. Por el contrario, las ilustraciones de Pound sobre el funcionamiento de los ideales en el proceso de decisión suelen ser históricas y muy generales (por ejemplo, Pound 1959: II 116 y ss.). 
pues, situaciones de hecho existentes en la sociedad a las que el Derecho da o debería dar cobertura. Pound se inspiró en uno de sus juristas más admirados, Rudolph von Ihering, para distinguir los intereses en tres categorías: individuales, colectivos y sociales.

Pound asegura que en última instancia todos los intereses los hacen valer individuos. Cabe preguntarse, pues, cuál es el criterio para distinguir entre intereses individuales y sociales. ${ }^{24}$ Pues bien, lo importante para establecer esa distinción es desde qué perspectiva se contemplan y a título de qué se afirman esos intereses. Así, los intereses individuales son aquéllos "que están implicados en y son vistos desde el punto de vista de la vida individual como tal -son afirmados a título de [asserted in the title of] la vida individual". Ejemplos de intereses individuales son el interés en la inmunidad corporal, en la propia opinión, en la propiedad o en las ventajas prometidas. Los intereses sociales son "las peticiones implicadas en el mantenimiento, la actividad y el funcionamiento de la sociedad; las demandas y deseos más amplios que son afirmados a título de la vida social y contemplados desde el punto de vista de la vida social en una sociedad civilizada". Ejemplos de intereses sociales son el interés en la seguridad general, en las instituciones económicas o en el progreso cultural. Además, Pound advierte, no toda demanda tiene porqué estar encasillada exclusivamente en una de las categorías ya que una misma demanda puede ser vista tanto desde la perspectiva del individuo como desde la perspectiva social. Dependiendo desde dónde la contemplemos y a título de qué la afirmemos representará un interés individual o un interés colectivo (Pound 1959: III 23-24).

3.2. Coincidencia entre Pound y Dworkin. Existen razones para suponer que la correspondencia entre intereses individuales y sociales, por una parte, y derechos y objetivos, o argumentos de principio y argumentos políticos, por otra, es casual, se trata de una coincidencia o, como mucho, de una ilustración de la influencia indirecta de Pound. A pensar así contribuye el que los breves pero explícitos reconocimientos de Dworkin hacia Pound en relación con la tesis de los principios no se reproducen en ninguna medida en la cuestión que ahora nos ocupa. Más bien al contrario, cuando Dworkin introduce la distinción entre argumentos de principio y argumentos políticos, se refiere a ella como "una distinción fundamental en la teoría política", lo que en interpretación de Burnet indica que Dworkin la considera como un lugar común (Dworkin 1975: 1058; Burnet 1985: 244). ${ }^{25}$ Sugiero que el

${ }^{24}$ De los públicos podemos prescindir en este análisis. Vienen a ser algo así como los intereses del Estado. Pero el propio Pound no les da mucha importancia en su obra.

${ }^{25}$ Aunque el propio Burnet afirma que "la relativa insignificancia de esa distinción embrionaria en los términos de la obra de Pound no precluye la posibilidad de que Dworkin se 
hipotético carácter casual (y no causal) de esta afinidad no imposibilita el análisis comparado ni neutraliza su interés.

3.3. Pound sobre intereses. Introducidos sucintamente el concepto de interés de Pound y la distinción establecida por él entre intereses individuales e intereses sociales, se trata ahora de precisar un poco más qué uso le dio el Decano a su teoría de intereses, lo cual se me antoja necesario antes de proceder a la comparación con Dworkin.

Aunque no me es posible reproducir el amplio inventario de intereses que Pound diseñó, tampoco creo que eso sea necesario para imaginar que en el grupo de intereses individuales se puede identificar una típica enumeración de los tradicionalmente llamados derechos naturales o fundamentales. Así, por ejemplo, el denominado por Pound interés individual de personalidad en la opinión estaría protegido por el derecho a la libre expresión, o el interés individual de substancia en la propiedad estaría garantizado por el derecho a la propiedad, ambos generalmente reconocidos en las constituciones occidentales modernas. Sin embargo, esta identificación es justo lo que Pound trataba de evitar con su teoría, si mi interpretación de la misma es correcta. Pound tenía una concepción instrumental del Derecho (por cierto, punto de clara divergencia con Dworkin): el Derecho es, ante todo, un instrumento, un medio para la consecución de fines. Partiendo de esa base, la confusión entre derechos e intereses es la confusión entre medios y fines que Pound fuertemente criticó porque adulteraba la naturaleza instrumental del Derecho. El fin del Derecho no es la protección de derechos sino la satisfacción de deseos humanos, el aseguramiento de intereses. Los derechos, siempre según Pound, no son sino los medios que se atribuyen para garantizar aquellos intereses dignos de protección. En su opinión, la jurisprudencia decimonónica, particularmente en los Estados Unidos, no había sabido o querido distinguir los intereses que subyacían a los derechos y, tomando a éstos, a los medios, como fines en sí mismos, se había alejado de la realidad social. Pound confiaba en que gracias al concepto de interés el jurista de comienzos del siglo XX podría cerrar el boquete abierto entre Derecho y sociedad que con tanto énfasis había él denunciado en sus primeros trabajos. "La doctrina de que el Derecho existe para asegurar intereses, ya sean individuales, públicos o sociales, obliga al jurista a mantenerse en contacto con la vida" (Pound 1921: 205).

Pound aplicó su teoría de intereses para ofrecer una explicación reveladora de la lucha por el desarrollo del Derecho laboral que tuvo lugar a finales del siglo XIX y durante el cambio de siglo en Norteamérica. En

haya aprovechado de ese argumento y lo haya desarrollado para sus propios propósitos" (1985: 244). 
esa época los tribunales anulaban cualquier legislación que, con el fin de proteger los intereses de los trabajadores, interfiriera en el tráfico mercantil. Se basaban para ello en el carácter poco menos que sagrado de los derechos individuales, especialmente el derecho de propiedad y la libertad de contratación. Esos derechos, Pound observaba acertadamente, eran algo más que derechos: representaban todo un ideal de Derecho e incluso de economía política. Pero ese ideal, que había sido el dominante en la América pionera, quedábase obsoleto ante las nuevas circunstancias sociales que acompañaron al cambio de siglo y que estaban relacionadas con un vertiginoso proceso de industrialización, inmigración y urbanización. Nuevas cuestiones relacionadas con ese nuevo contexto social empezaron a plantearse ante los tribunales: eran cuestiones que se incluían bajo la etiqueta de políticas públicas (public policies). La protección de los trabajadores industriales se presentaba, pues, como un conflicto entre políticas públicas y derechos individuales. Mientras que éstos últimos eran la expresión bien consolidada de aquel ideal tradicionalmente dominante que se hallaba en la base filosófica del sistema, la categoría de políticas públicas era vaga y estaba mal definida, de forma que los juristas desconfiaban de ella. ${ }^{26}$

Pound se ocupó de desvelar la ficción bajo la cual esa jurisprudencia anticuada estaba operando y contribuyó con ello al nacimiento de una nueva etapa en el Derecho estadounidense. Si los derechos individuales debían ser considerados, como así él lo pensaba, medios para la protección de intereses individuales, las políticas públicas eran medios (por tanto, a priori en pie de igualdad con los anteriores) para la protección de intereses sociales. ${ }^{27}$ Así, Pound insistía en que el conflicto entre derechos y políticas, casi siempre desigualmente planteado y resuelto, debía en realidad concebirse como un conflicto entre intereses individuales e intereses sociales.

Yendo aún más allá, Pound aplicaba a ese debate su principio de generalización. Según este último (basado en un hecho que se ha apuntado antes, a saber, que las demandas de los individuos pueden a veces subsumirse tanto en la categoría de intereses individuales como en la de intereses sociales) todas las demandas, para ser comparadas, deben ser traducidas siempre que eso sea posible en términos de intereses sociales. En el contexto del debate

${ }^{26}$ Esta situación, frente a la que Pound se rebeló enfáticamente en sus primeros escritos, había llegado a constituirse en un círculo vicioso, ya que la propia primacía de la asertividad individual, representada en los derechos individuales como base imperecedera del sistema, era causa del escaso interés por definir y concretar qué se escondía bajo las políticas públicas (Laube 1949: 294).

${ }^{27}$ De hecho, Pound identificó bajo algunas de las políticas públicas que con poco éxito se habían formulado en los tribunales algunos de los intereses sociales incluidos en su catálogo (Pound 1943: 7-8). 
antes planteado esto implica un nuevo cambio de enfoque: el verdadero conflicto, según Pound, se producía no ya entre intereses individuales y sociales sino entre distintos intereses sociales. Se trata de un segundo paso en el proceso de desenmascaramiento de las decisiones obstructoras de la incipiente legislación. Por una parte estaba el interés en la seguridad general en sus manifestaciones de seguridad en las adquisiciones y seguridad en las transacciones. En realidad éstos eran los intereses (en su versión social) que estaban protegidos, respectivamente, por el derecho de propiedad y por la libertad de contratación. Por otra parte estaban los intereses sociales que se escondían bajo las políticas públicas, en concreto, el interés en la seguridad de las instituciones, en la moral general y, de manera muy especial, el llamado por Pound interés social en la vida individual. ${ }^{28}$ Esta lucha entre intereses sociales tenía lugar en los tribunales de forma subconsciente y el sacarla a la luz era paso previo y necesario para el desarrollo más completo de la teoría de intereses (Pound 1943: 6). Fue en ese paso previo donde el trabajo de Pound resultó más iluminador.

3.4. Colectivismo vs. individualismo. Retomando lo dicho al comienzo de este apartado tercero, Ronald Dworkin establece una distinción entre los dos tipos fundamentales de argumentos utilizados para justificar decisiones políticas: los argumentos de principio y los argumentos políticos. Los argumentos políticos son aquéllos que "justifican una decisión política mostrando que la misma favorece o protege alguna meta u objetivo colectivo de la comunidad como un todo". Por el contrario, los argumentos de principio "justifican una decisión política mostrando que esa decisión respeta o asegura algún derecho" (Dworkin 1975: 1059). La propuesta de comparación que plantea Burnet sugiere que la distinción de Pound entre intereses individuales (que se hallan en la base de los derechos) e intereses sociales (en la base de las políticas públicas) anticipa la distinción dworkineana entre derechos (corresponderían a los intereses individuales) y objetivos colectivos (corresponderían a los intereses sociales).

Aquí no nos encontramos sólo frente a una coincidencia sino también, dentro de esa coincidencia, frente a una dramática diferencia en cuanto a la posición de ambos autores que merece ser destacada. Dworkin plantea la distinción para presentar inmediatamente su tesis de fondo según la cual las decisiones judiciales, de forma característica, están basadas y deben basarse en argumentos de principio (esto es, en derechos característicamente individuales) y no en argumentos políticos (esto es, en objetivos de la colectividad) (Dworkin 1975: 1060). Lo que pedía Pound, si aceptamos

\footnotetext{
${ }^{28}$ Al cual concedía Pound una gran importancia (Pound 1943: 33, para un tratamiento del mismo véase Pound 1959 III: 315-24).
} 
el paralelismo en la distinción, era más bien lo opuesto: que la atención se desplazara de los intereses individuales a los colectivos, de los derechos a los objetivos y a las políticas. En Pound los argumentos enfrentados en conflictos jurídicos deben generalizarse lo más posible para que la discusión se plantee en forma no de derechos sino de políticas públicas.

Varias aclaraciones son pertinentes a este respecto. La primera, que la tesis de los derechos de Dworkin se circunscribe a la actividad judicial. No alcanza, pues, al legislador, y como el mismo autor afirma "la justificación de un programa legislativo de cierta complejidad exigirá, por lo común, ambas clases de argumentos", esto es, argumentos de principio y argumentos políticos (Dworkin 1975: 1059). La teoría de intereses de Pound, por su parte, es una teoría para la toma de decisiones jurídicas en general: no se circunscribe a la función judicial sino que es igualmente aplicable a la legislativa (Pound 1913). Esta última quedaría fuera de la oposición, la cual se circunscribe al ámbito del razonamiento judicial.

Una segunda aclaración pasa porque la preferencia de Dworkin por los derechos contra los objetivos parece más estricta que la de Pound en sentido contrario. En relación con Dworkin, cualquiera que conozca el contexto general de su obra entenderá bien lo que digo: los derechos constituyen un núcleo esencial de la filosofía jurídica de este jurista, quien es un crítico declarado de cualquier concepción pragmática e instrumental del Derecho. El instrumentalismo de Pound, sin embargo, se presenta a veces de manera menos clara que el anti-instrumentalismo de Dworkin, aunque finalmente considero que sin duda domina su pensamiento. Burnet pone ese dominio en duda cuando resalta algunas matizaciones que el propio Pound realiza a posiciones utilitaristas en relación con la teoría de intereses (Burnet 1985: 240 en referencia a Pound 1959: III 332-34). Aunque en mi opinión esas aclaraciones son poco importantes, se podría incluso acordar con Burnet que "parece que no existe una prioridad intrínseca de los intereses sociales" (Burnet 1985: 240, cursiva añadida). Bastaría con decir que existe en Pound una cierta prioridad de los intereses sociales. Creo que esa conclusión es acertada puesto que respeta la identidad filosófica de Pound al tiempo que expresa la diferencia entre su postura y la de Dworkin (pues en este último sí parece haber una prioridad intrínseca y fundamental por los derechos).

La última de las aclaraciones, la más importante, nos remite a la importancia del contexto en las tesis de los dos autores, y creo que puede sugerir reflexiones de interés respecto a nuestra interpretación de Dworkin. Las críticas de Pound contra un tipo de razonamiento judicial basado en el concepto de derecho individual eran una reacción contra el paradigma dominante en el Derecho americano de finales del XIX y tránsito al XX, esto es, lo que él llamaba jurisprudencia mecánica o lo que más recientemente ha sido 
bautizado como el pensamiento jurídico clásico (Wiecek 1998). ${ }^{29}$ Ese paradigma se basaba en ideales heredados de un contexto social, económico y geográfico que no representaba el fuerte cambio que Estados Unidos estaba experimentando. Los nuevos problemas, derivados de la industrialización, requerían nuevas soluciones, simbolizadas en las emergentes leyes sociales, pero el progreso de éstas era repetidamente obstruido por el atrincheramiento de la posición económica de los propietarios, traducido jurídicamente en la sacralización de los derechos individuales. En esto el Derecho se estaba quedando atrás en relación con el ambiente intelectual y político del país, que estaba sustituyendo en todos los ámbitos el prisma del individualismo por el del colectivismo (Kuklick 2001: 105-10). La teoría de Pound estaba inserta en ese cambio. La esencia de su teoría de intereses, simbolizada por el principio de generalización, según el cual el énfasis en el discurso jurídico pasaba de los intereses individuales a los intereses sociales, del individuo a la sociedad, era el reflejo de la nueva filosofía social dominante a la que Pound se adhería (Pound 1907: 607; Pound 1906: 20-21).

Cuando Dworkin desarrolla su teoría de los derechos, esto es, a finales del siglo XX, la situación del Derecho americano contrasta con la de comienzos de siglo. Durante las décadas intermedias, algunas de las ideas de Pound, apoyadas por sus más radicales discípulos, los realistas, han sido llevadas más lejos de lo que él mismo hubiera querido. Dworkin se encuentra con un sistema jurídico en el que las políticas públicas ocupan una posición dominante. La comunidad académica se centra en cuestiones políticas hasta el punto de que parte de la misma se identifica seriamente bajo el lema de que "el Derecho es política". ${ }^{30} \mathrm{El}$ énfasis de Dworkin en los derechos, en tomar los derechos en serio, como reza el título de una de sus obras principales, debe explicarse contra ese telón de fondo. Un telón de fondo, por cierto, eminentemente localista. Si el realismo jurídico no ha tenido predicamento fuera de las fronteras de Estados Unidos lo mismo, con más énfasis aún, hay que decir en relación con los critical legal studies o, en general, todas las posiciones que reducen el Derecho a cuestiones políticas [law-is-policy reductionists].

Así pues, son los enemigos que ambos intentaban combatir los que permiten explicar (y hasta cierto punto justificar) las posiciones respectivas de Dworkin y Pound y su aparente enfrentamiento. Teniendo esto en cuenta

${ }^{29}$ Una muy buena aproximación al mismo y a su articulación jurisprudencial puede encontrarse en castellano en Solar Cayón 2002.

${ }^{30}$ Un slogan común en el movimiento de los critical legal studies, herederos, por su parte, del realismo jurídico, y por tanto, en ese sentido, descendientes lejanos de Pound, de quien sin embargo es plausible imaginar que si pudiera pronunciarse al respecto renegaría de toda relación de parentesco con los mismos. 
cabe pensar que ellos no se encuentran en su pensamiento tan alejados el uno del otro como sugiere una primera aproximación a sus obras. Dworkin se vio obligado a poner en primera línea los valores tradicionales del common law frente a la amenaza de una extendida actitud instrumentalista hacia el Derecho. Pero lo cierto es que el último Pound, quien vivió el auge de los realistas y la elevación de las cuestiones políticas hasta un lugar predominante en el Derecho americano, no se pronunció en términos muy diferentes a los de Dworkin en relación con esos valores tradicionales del common law, particularmente el respeto por el proceso debido y, ante todo, por el individuo, representado en la defensa a ultranza de sus derechos fundamentales. Por eso, después de la ruptura con la tradición que inicialmente supuso, se ha podido afirmar que "la teoría de los intereses sociales es mucho menos radical de lo que parece a primera vista" (Patterson 1968: 397).

La discusión, insisto, y esto creo que se deduce de lo dicho, es típicamente americana. Las teorías de Pound y Dworkin esbozan, con sus líneas principales, un período en la historia del Derecho estadounidense. Esto llama la atención sobretodo dado el interés universal suscitado por la filosofía jurídica de Dworkin. Si el contexto desde el que escribe un autor es siempre importante, en el caso de Dworkin es fundamental. Su tesis de los derechos la motiva ante todo el enfrentamiento con posiciones académicas americanas. Sus propuestas y los ejemplos que utiliza para ilustrarlas son innegablemente americanos. Su objetivo es afrontar los problemas específicos de una cultura jurídica muy concreta. Este hecho, que parece aconsejable tener en cuenta para una completa comprensión de su obra, es pasado por alto con excesiva frecuencia.

Por supuesto, esta reflexión se inserta en el contexto de descubrimiento de la teoría de los derechos de Dworkin, y, en general, de su filosofía jurídica. Para imaginar porqué esa teoría tiene un éxito universal es necesario entrar en otra dimensión, la de la justificación. Aquí las tesis de Dworkin han encontrado un terreno abonado en otros contextos distintos al de su origen. En nuestro entorno, el constitucionalismo europeo (claro, no ajeno en su desarrollo histórico al americano) y la cultura de los derechos que en él impera, encuentran en la filosofía dworkiniana un marco teórico a primera vista adecuado. Pero en esa cuestión no entraré aquí pues ya nos aleja mucho de la comparación entre los dos autores que es objeto del presente estudio.

3.5. El bloqueo utilitarista. Resulta casi inevitable destacar que Dworkin plantea los problemas jurídicos de una forma semejante a como lo hacía la antigua jurisprudencia contra la que Pound se enfrentó, a saber, como una oposición entre derechos y políticas públicas. Hay, en este sentido, un aire de familiaridad entre Dworkin y el pensamiento jurídico clásico del common law (Cotterrell 1992: 168). En cierto sentido el debate actual entre las po- 
siciones que ven el respeto a los derechos como el fundamento esencial del Derecho y las que proclaman la identificación del Derecho con la política, es un síntoma del fracaso de la teoría de intereses de Pound. Si yo la entiendo correctamente, su objetivo era el de romper esa dicotomía y trasladar el foco de la discusión al concepto de interés, base fáctica subyacente tanto de derechos individuales como de políticas públicas.

La explicación de ese fracaso se halla en las dificultades de plantear una teoría de los derechos partiendo de bases utilitaristas. Pound, como muchos de los juristas de su generación, adoptó su teoría de la justicia de la filosofía pragmática americana y, por extensión, del utilitarismo, del que aquélla bebía en esa cuestión (Summers 1982: 42). La teoría de los intereses es lo más parecido a una teoría de la justicia que se puede encontrar en Pound. Es cierto que el utilitarismo de Pound está matizado por su profundo respeto hacia la tradición del common law y que el Decano no es consistente del todo en su defensa, pero aún así su teoría de intereses puede seguir calificándose como utilitarista, y ha recibido muchas críticas específicas dirigidas en esa línea (entre otras, Stone 1935, Patterson 1947, di Filippo 1988).

Aquí no hay lugar para entrar en ellas, pues sólo tienen interés de cara a un estudio monográfico sobre Pound. Prefiero más bien incidir, aunque sólo sea de forma general, en que la posibilidad misma de construir una buena teoría de los derechos partiendo de bases filosóficas utilitaristas ha sido puesta seriamente en duda. La crítica más común pasa por afirmar que el utilitarismo es incompatible con la importancia moral de los individuos, de la individualidad misma de las personas, al subordinar su felicidad a la felicidad global de un ente colectivo, la sociedad en su conjunto (Hart 1980: 8-10). Como se ha expresado, de forma muy gráfica, el utilitarismo implica "fundir los intereses de los individuos en un sistema unitario, desconociendo que son intereses de personas distintas y separadas" (Nino 1989: 242). Ni que decir tiene que esa concepción es profundamente anti-liberal y que casa bastante mal con el concepto de derecho subjetivo, o al menos con la concepción del mismo dominante en nuestra cultura, en la que aquél cobra su máxima expresión precisamente contra corriente del bien común, cuando se debe hacer efectiva "la promesa que la mayoría hace a las minorías de que la dignidad y la igualdad de éstas serán respetadas" (Dworkin 1984: 303). El reconocimiento de los derechos individuales en una sociedad perfectamente utilitarista en la que toda medida o acción tuviera como justificación última la persecución del bien común sería, más que otra cosa, inoperante y superfluo (Nino 1989: 261-62).

Aunque el utilitarismo es una de las grandes doctrinas políticas de nuestro tiempo y ha tenido un predicamento importante hasta mediado el pasado siglo, las últimas décadas de éste experimentaron una transición en el mun- 
do de la filosofía jurídica y política desde el utilitarismo en alguna de sus formas hacia teorías bien distintas basadas en los derechos fundamentales (Hart 1980: 7). La importancia que la idea de derechos humanos posee en nuestra cultura relega a la teoría de intereses de Pound a una posición secundaria. Una posición, por otra parte, a la que el propio Pound contribuyó mediante su infructuoso intento de compatibilizar la teoría de intereses con el pensamiento tradicional del common law, un pensamiento individualista de corte liberal en el que los derechos juegan un papel clave, en vez de hacer el esfuerzo por desarrollar una teoría de la justicia consistente en su utilitarismo.

\section{Recapitulación y consideraciones finales}

4.1. En relación con las reglas y los principios. A pesar de que Pound fue relativamente parco en sus tesis sobre los principios y la distinción entre los mismos y las reglas, su influencia en el pensamiento jurídico en ese aspecto ha sido fundamental. Y ello por dos razones. Primera, porque ese tema se ha convertido en uno de los focos de discusión más importantes de la filosofía jurídica contemporánea, lo cual maximiza la influencia de cualquier contribución al respecto. Y segunda, porque lo poco que Pound dijo fue muy importante. En particular, formuló la tesis básica que ha sido adoptada por Dworkin como caballo de batalla frente al positivismo dominante (o al menos su caracterización del mismo), a saber, que el derecho no se compone sólo de reglas sino también de principios, los cuales son distintos a las reglas pero tan vinculantes jurídicamente como ellas, son Derecho en el mismo sentido en que lo son las reglas. El propio reconocimiento por parte de Dworkin del mérito de Pound resalta su influencia. Sin embargo, Dworkin encasilló a Pound como representante de un modelo simplista en relación con la discreción judicial, según el cual no habría término medio entre el recurso mecánico a la regla y la decisión libre de estándares vinculantes por parte del juez. Un estudio exhaustivo de la obra de Pound muestra que el Decano elaboró un modelo algo más sofisticado de decisión judicial, un modelo gradual en el que se adivinaban algunos planteamientos actuales. La inclusión en ese modelo de los ideales, materiales jurídicos distintos a las reglas y a los principios pero dotados igualmente de autoridad normativa, prefigura otros puntos importantes de la teoría de Dworkin, como la tesis de la respuesta jurídica correcta y su concepción misma del Derecho como integridad. Con las pruebas existentes, no es posible determinar si en este particular existe una verdadera influencia o si hay que hablar más bien de semejanzas significativas.

4.2. En relación con los intereses y los derechos. Existe un interesante paralelo entre la distinción que Dworkin establece entre derechos y objeti- 
vos y la establecida por Pound entre intereses individuales y sociales. En su momento, Pound presentó la teoría de intereses como una ruptura con el paradigma del pensamiento jurídico clásico que, articulado judicialmente a través del conflicto entre derechos y políticas públicas, obstaculizaba los intentos de modernización del derecho americano, simbolizados en la naciente legislación social. El paralelo entre Dworkin y Pound nos permite contrastar el carácter colectivista de éste, representado por la primacía otorgada a los intereses sociales, con el individualismo de Dworkin y la posición central que en su filosofía ocupan los derechos. Ese contraste es en gran medida el contraste entre dos momentos históricos del derecho americano, e incide en la necesidad de contextualizar las teorías, de manera particular la del universalizado Dworkin.

4.3. Consideraciones finales. Tanto Pound como Dworkin son dos juristas de indudable importancia, dos iconos del pensamiento jurídico contemporáneo. Sus obras han tenido (las del primero) y tienen (las del segundo) una gran repercusión. Pero mientras Pound era un entusiasta de la erudición, Dworkin parece más bien serlo de la originalidad. De Pound resaltaba ante todo su habilidad para trasladar, reorganizar y combinar ideas ajenas. Su pensamiento era un mosaico de influencias minuciosamente referenciadas, una portentosa obra de bricolaje. ${ }^{31}$ Dworkin le pone las cosas un poco más difíciles a sus intérpretes interesados en trazar las influencias de sus teorías, algo que se antoja necesario para entenderlas plenamente. Aunque pocas veces se haga mención a ello, hay mucho en Dworkin de dos de sus antecesores en la cima de la filosofía jurídica norteamericana: Roscoe Pound y Lon Fuller. ${ }^{32}$

Se ha intentado aquí en relación con el primero un breve ejercicio académico, identificándose unos pocos puntos de correspondencia entre su teoría y la de Dworkin en los cuales podrían anidar influencias. Que tal influencia existe de manera directa parece claro al menos en uno de esos puntos: la identificación y denuncia del "modelo de las reglas" y la formulación de la tesis de los principios. Respecto a los demás, hay lugar para la especulación. Es posible, en cualquier caso, que el valor principal de esa especulación no sea tanto el de poder alcanzar una respuesta definitiva en un sentido u otro, como el de aproximarse por medio de aquélla, aunque sea mínimamente, al sugerente pensamiento de Pound, y quizás, de forma silenciosa y sin que apenas nos demos cuenta, éste pueda iluminar la interpretación de la compleja obra de Dworkin. Ése es en realidad el espíritu de su singular influencia, un espíritu cuyas resonancias no sólo se escuchan en los trabajos

\footnotetext{
${ }^{31}$ Hull 1997 utiliza repetidamente el calificativo de bricoleur para referirse a Pound.

${ }^{32}$ En relación con la influencia de Fuller en Dworkin algo se ha dicho recientemente en Escudero 2002: 328-331.
} 
de Dworkin sino en una gran parte de la filosofía jurídica norteamericana contemporánea, de la que el Decano Pound fue el reconocido fundador.

\section{Bibliografía citada}

Atienza, Manuel y Ruiz Manero, Juan (1996): Las piezas del Derecho. Una teoría de los enunciados jurídicos, Ariel, Barcelona.

BARAK, Aharon (1989): Judicial Discretion, Yale University Press, New Haven, Connecticut ( $1^{\text {a }}$ ed. en hebreo 1987, trad. Yadin Kaufmann).

BAYÓn, Juan Carlos (2002): "Derecho, convencionalismo y controversia", en Pablo E. Navarro y María Cristina Redondo (comp.), La relevancia del derecho. Ensayos de filosofía jurídica, moral y política, Gedisa, Barcelona, pp.57-92.

Burnet, David (1985): "Dworkin and Pound", 71 Archiv für Rechts und Sozialphilosophie 234.

Coleman, Jules (1996): "Authority and Reason", en Robert P. George (ed.), The Autonomy of Law. Essays on Legal Positivism, Clarendon, Oxford, 1996, pp.287-319.

- (2001) The Practice of Principle, Oxford University Press, Oxford.

Cotterrell, Roger (1992): The Politics of Jurisprudence. A Critical Introduction to Legal Philosophy, University of Pennsylvania Press, Philadelphia, 1992 (1 ed. 1989).

DI FILIPPO, Terry (1988): "Pragmatism, Interests Theory and Legal Philosophy. The Relation of James and Dewey to Roscoe Pound", 24 Transactions of the Charles S. Peirce Society 487.

Dworkin, Ronald (1963): "Judicial Discretion”, 60 Journal of Philosophy 624.

- (1967): "The Case for Law - A Critique", 1 Valparaiso University Law Review 201.

- (1970): “Is Law a System of Rules?", reimpresión en Robert S. Summers (ed.), Essays in Legal Philosophy, Basil Blackwell, Oxford, (originalmente "The Model of Rules", 35 University of Chicago Law Review 14 (1967); reimpresión como capítulo II de Los derechos en serio)

— (1975): "Hard Cases", 88 Harvard Law Review 1057 (reimpresión como capítulo IV de Los derechos en serio).

- (1984): Los derechos en serio, Ariel, Barcelona ( $1^{\mathrm{a}}$ ed. en inglés 1977, trad. Marta Guastavino).

- (1986): Law's Empire, The Belknap Press of Harvard University Press, Cambridge, Massachussetts.

EsCUDERO AldAY, Rafael (2002): “Argumentos para la recuperación de la teoría de Lon L. Fuller”, Anuario español de filosofia del Derecho, tomo XIX, pp.309-331.

Frank, Jerome (1970): Law and the Modern Mind, Peter Smith, Gloucester ( $1^{\mathrm{a}}$ ed. 1930).

García Carrió, Genaro (1990): "Principios jurídicos y positivismo jurídico", en Notas sobre derecho y lenguaje, Abeledo Perrot, Buenos Aires, $4^{\mathrm{a}}$ ed. $\left(1^{\mathrm{a}} \mathrm{ed}\right.$. $1965)^{33}$.

\footnotetext{
${ }^{33}$ Aunque, como el propio autor señala en su introducción (p. 9), la primera aparición del ensayo aquí citado no se produce hasta 1970.
} 
García Figueroa, Alfonso (1998): Principios y positivismo jurídico. El no positivismo principialista en las teorías de Ronald Dworkin y Robert Alexy, Centro de Estudios Políticos y Constitucionales, Madrid.

García Ruiz, Leopoldo (2002): Derecho, intereses y civilización. El pensamiento jurídico de Roscoe Pound, Comares, Granada.

Hart, H.L.A. (1980): "Entre el principio de utilidad y los derechos humanos", Revista de la Facultad de Derecho de la Universidad Complutense, vol.58, pp.728.

- (1994): The Concept of Law, Clarendon, Oxford, $2^{\mathrm{a}}$ ed. con Postcript editado por Joseph Raz y Penelope Bulloch (1 $1^{\text {a }}$ ed. 1961).

Himma, Kenneth Einar (2002): "Inclusive Legal Positivism”, en Jules Coleman y Scott Shapiro (eds.), The Oxford Handbook of Jurisprudence and Philosophy of Law, Oxford University Press, Oxford, pp.125-165.

Hull, N.E.H. (1997): Roscoe Pound \& Karl Llewellyn. Searching for an American Jurisprudence, The University of Chicago Press, Chicago.

Kuclick, Bruce (2001): A History of Philosophy in America, Clarendon, Oxford.

LASSER, Mitchel (2002): "Comparative Readings of Roscoe Pound's Jurisprudence", 50 The American Journal of Comparative Law 719.

Laube, Herbert (1949): “The Jurisprudence of Interests”, 34 Cornell Law Quarterly 291.

Martin, Michael (1965): "Roscoe Pound's Philosophy of Law", 51 Archiv für Rechts und Sozialphilosophie 37.

Moreso, José Juan (2002): “En defensa del positivismo jurídico inclusivo”, en Pablo E. Navarro y María Cristina Redondo, La relevancia del derecho. Ensayos de filosofia jurídica, moral y política, Gedisa, Barcelona, pp.93-116.

Nino, Carlos S. (1989): Ética y derechos humanos. Un ensayo de fundamentación, Ariel, Barcelona.

Patterson, Edwin (1947): "Pound's Theory of Social Interests", en Paul Sayre (ed.), Interpretations of Modern Legal Philosophies. Essays in Honor of Roscoe Pound, Oxford University Press, Oxford, p.558-573.

- (1953): Men and Ideas of the Law, The Foundation Press, Brooklyn, New York.

- (1968): "Roscoe Pound", en David A. Sills (ed.), International Encyclopedia of the Social Sciences, MacMillan, New York, pp.395-398.

Perry, Stephen (1997): “Two Models of Legal Principles", 81 Iowa Law Review 787.

Pound, Roscoe (1906): "The Spirit of the Common Law", 18 Green Bag 17.

— (1907): "The Need of a Sociological Jurisprudence", 19 Green Bag 607.

- (1913): "Legislation as a Social Function", 18 American Journal of Sociology 755.

- (1921): The Spirit of the Common Law, Marshall Jones Company, Boston.

- (1923): "The Theory of Judicial Decision", 36 Harvard Law Review 641, 802, 940.

- (1926): Law and Morals, The University of North Carolina Press, Chapell Hill, North Carolina, $2^{\mathrm{a}}$ ed. (1 ${ }^{\mathrm{a}}$ ed. 1924). 
— (1933): "Hierarchy of Sources and Forms in Different Systems of Law", 7 Tulane Law Review 475.

- (1936): "How Far Are We Attaining a New Measure of Values in Twentieth Century Juristic Thought?", 42 West Virginia Law Quarterly 81.

- (1940): "The Twilight of Liberty", 28 Nation's Business 8.

- (1941): "My Philosophy of Law", en My Philosophy of Law. Credos of Sixteen American Scholars, Boston Law Books, Boston, pp.249-262..

- (1943): “A Survey of Social Interests", 57 Harvard Law Review 1.

- (1944): The Task of Law, Franklin and Marshall College, Lancaster, Pennsylvania.

— (1959): Jurisprudence (5 vols.), West Publishing, St. Paul, Minnesota.

- 1967): “The Case for Law”, 1 Valparaiso Univerity Law Review 201.

- (1997): Social Control Through Law, Transaction Publishers, New Brunswick, New Jersey ( $1^{\mathrm{a}}$ ed. 1942).

- (2002): The Ideal Element in Law, Liberty Fund, Indianapolis ( $1^{\mathrm{a}}$ ed. 1958).

RAz, Joseph (1972): "Legal Principles and the Limits of Law", 81 Yale Law Journal 823.

SAYre, Paul (1948): The Life of Roscoe Pound, State University of Iowa, Iowa City.

Solar Cayón, José Ignacio (2002): Política y derecho en la era del New Deal. Del formalismo al pragmatismo jurídico, Dykinson, Madrid.

Stone, Julius (1935): “A Critique of Pound's Theory of Justice”, 20 Iowa Law Review 531.

Summers, Robert S. (1982): Instrumentalism and American Legal Theory, Cornell University Press, Ithaca, New York.

— (1984): "Roscoe Pound", en A.W.B. Simpson (ed.), Bibliographical Dictionnary of the Common Law, Butterworths, London, pp.427-431.

Treviño, Javier A. (1997): "Introduction" a Roscoe Pound, Social Control Through Law, Transaction, New Brunswick, New Jersey.

Waluchow, W.J. (1994): Inclusive Legal Positivism, Clarendon, Oxford.

WIECEK, William M. (1998): The Lost World of Classical Legal Thought, Oxford University Press, Oxford.

Wigdor, David (1974): Roscoe Pound. Philosopher of Law, Greenwood Press, Westport, Connecticut. 